\title{
María, la mujer (¿la diosa?) que consuela*
}

\author{
Carmiña Navia Velasco ${ }^{* *}$
}

\section{Resumen}

En este artículo la autora toma como punto de partida reflexiones en torno a las representaciones contradictorias de María de Nazaret en el pensamiento teológico, las cuales son incomprensibles para un creyente corriente. La autora se pregunta por los motivos reales o imaginarios que generan y agrandan permanentemente este nudo.

Palabras clave: María de Nazaret, documentos conciliares, divinidad, misterio, advocaciones.

* Velasco, C. N. (2012, 19 de sep.). Conferencia. en III Congreso Internacional de Teología Mariana. Chiquinquirá, BOy: Facultad de Teología de la Universidad Santo Tomás.

** Magíster en español y Lingüística por la Universidad del Valle, Magíster en Teología por la Pontificia Universidad Javeriana, especialización en el Instituto Iberoamericano de Cooperación Lengua y Literatura española, Licenciada en Letras por la Universidad del Valle. Directora de la Casa Cultural Tejiendo Sororidades, Cali. Correo electrónico: cnaviavelasco@ yahoo.es 
¿Cómo sería tu rostro/ María, / entre tantos rostros, único para su amado?/ ¿Soltarías tu pelo antes de dormir,/ lavarías tus pies, ungirías tu cuerpo con aceite?/ ¿Cómo sería tu cuerpo,/ María, morada frágil para tu amor, / vigoroso barco para tu hijo?/ ¿Cómo sería tu voz al entonar las preces, / al agradecer, / al pedir perdón?

Roseana Murray

\section{Introducción}

La figura de María de Nazaret, una humilde mujer campesina perdida en los riscos medio desérticos de Galilea (hoy territorio jordano-israelí), ha dado y continúa dando mucho de qué hablar en nuestra cultura. Se trata de una figura completamente mitificada para bien y para mal, que ha estropeado la vivencia de su sexualidad a cientos de miles de mujeres y que ha servido de inspiración y de consuelo a otras tantas. en el siglo II, aproximadamente a unos cien años de su muerte, ya esta figura era irrecuperable en su propia mismidad. No es a esa mujer sencilla y galilea a quien me voy a acercar en este texto: es a lo que han hecho de ella sus imágenes lo que quiero desentrañar un poco.

Por un lado, el Protoevangelio de Santiago la convirtió muy pronto en una virgen que nace sin mancha (condición que, desde algunas miradas, compartimos todos los humanos) y que concibe y pare sin contacto sexual y sin ruptura de su himen, directamente por acción divina. Por otro lado, en esos mismos tiempos el filósofo romano Celso, en sus escritos contra los cristianos, la convirtió en una mujer adúltera que había concebido a Jesús en una relación extraconyugal con el soldado romano Pantera y que por ello habría sido echada de su casa por José el carpintero; desde los inicios otras versiones hablaron de una violación por parte de ese mismo soldado (Orígenes, 2001) $)^{1}$.

1 Las obras de Celso se han perdido, pero se conservan las citas que de sus escritos realizó Orígenes en su debate permanente con él. 
Han pasado veinte siglos, pero su nombre, su figura, su imagen continúan siendo amados y rechazados con igual fuerza. elizabeth A. Johnson, en su completo estudio mariológico, dice:

La figura de María es extraordinariamente compleja. Se la estudie desde el punto de vista de la teología, de la espiritualidad o de la cultura, esta mujer de Galilea ha sido interpretada y explicada, imaginada y rechazada, amada y venerada de formas tan diversas que es imposible codificarla $[\ldots]$ ¿Cómo puede construirse su imagen de manera que sea fuente de bendición y no elemento dañino para la vida de la mujer en términos tanto religiosos como políticos? (2005, p. 19).

María de Nazaret, durante el concilio Vaticano II, fue una especie de tema espinoso que era imperativo bordear sin llegar a profundizar en él:

Una de las mayores preocupaciones de la Iglesia ha sido la de que los fieles acabaran transformando a María en una diosa. Fue también la preocupación del Concilio Vaticano II, que ante el temor de que el tema de María pudiese adquirir proporciones excesivas, no quiso que se redactara un documento especial relativo a la madre de Jesús. Por otra parte los fieles de todo el mundo han considerado siempre a María como situada por encima de los otros santos. en la práctica ha sido -y lo es aún - considerada cercana a la Divinidad. y en el culto a la Virgen es posible encontrar aún hoy mezclas de paganismo y superstición que rozan las fronteras de lo divino (Arias, 2005, p. 121).

Elizabeth Johnson recoge con bastante exactitud la dificultad del abordaje de la mariología en el desarrollo del concilio. Hablando de las posturas sobre si había que escribir un documento independiente sobre María o incluirla en el de la Iglesia, dice que se trató de un "duelo de titanes" y lo registra así:

Tuvieron su papel en esta división las características nacionales, con personalidades españolas, italianas y polacas a favor de la estrategia maximalista, nacida del corazón y entusiasta, mientras los temperamentos alemán, inglés, francés, belga y holandés tendieron a una visión basada más en la Biblia y más rigurosa teológicamente. Durante 
la discusión el ambiente llegó a ser explosivo. Laurentin² describe casi violento. el partido defensor de los privilegios denunció la moción de inclusión como una conjura contra Nuestra Señora, utilizando acusaciones apasionadas y haciendo apelaciones sentimentales para defender su causa (2005, p. 156).

Tal vez por todo esto, en los documentos conciliares y en la teología del Concilio terminó por evadirse mucho a María. Sobre esta realidad, Catharina Halkes, una de las teólogas feministas que más ha trabajado esta temática, escribe:

¿Cuál es la verdadera María? Se ve ya la escisión en Éfeso, donde María asume el puesto de la diosa Diana o Artemisa y configura el misterio de la madre divina, que es indispensable para los hombres. esto, de hecho da origen a dos Marías. Primero, la María de la doctrina de fe, que siempre vigila para que la persona de María se mantenga subordinada a la de Cristo, de manera que su esplendor no disminuya u oscurezca el esplendor de Cristo, y en la que María debe su excelencia a la gracia de Dios y al nacimiento de Cristo. Segundo, además de esto está la María que vive en una piedad creciente y a veces extravagante, no solo de parte del pueblo sencillo, sino también de hombres, santos y teólogos, como Bernardo. esta piedad tiene un resplandor propio; es una reminiscencia que proviene de una necesidad primordial de lo que da, nutre y preserva la vida. Mientras existan estas diferencias, se- guirá la confusión, pero esto reta aún más a profundizar en el análisis (2000, p. 105).

La presión intelectual de los teólogos y de algunas teólogas europeas logró racionalizar un poco más esta referencia y hubo un gran avance en el sentido de que los ojos de los y las creyentes se volvieron hacia la mujer histórica, concreta y real que fue la madre de Jesús. en los años que siguieron al concilio se profundizó en la María de los evangelios y el Magníficat se convirtió en el himno de entrada a una nueva aproximación a la realidad de

2 Cfr. Laurentin, R. (1965). Historia del concilio. La Virgen en el concilio. París: P. Lethielleux. 
esta campesina judía. La Virgen de Guadalupe, la Aparecida y otras advocaciones latinoamericanas se convirtieron, dentro del paradigma de la teología de la liberación, en una motivación y respaldo para la lucha de liberación de estos pueblos. en cualquier caso, lo poco que se desarrolló fue una mariología centrada en Jesús.

Pero la realidad última es que durante la celebración misma del Concilio y en los años inmediatamente posteriores, en la reflexión y espiritualidad católicas se soslayó la figura de María, porque no se quiso abordar todo el tema de la mujer, ligado a ella. Fue necesario esperar algunas propuestas incipientes de la teología feminista para repensar a fondo el papel de la madre de Jesús en el panorama amplio del cristianismo y para revisar su estrecha vinculación con imágenes dañinas de la mujer, así como para proyectar nuevas perspectivas que la acompañen en sus procesos de autoestima, autovaloración y liberación.

Hay una pregunta de fondo que nos formulamos como punto de partida de estas reflexiones: ¿qué generó en la historia del cristianismo esta avalancha de representaciones, de pensamiento teológico, de sentimientos, que convirtieron a María en un nudo de contradicciones? ¿Se trató simplemente de pretender explicar unas construcciones imposibles de comprender $\mathrm{o}$, acaso, existieron siempre otras razones o motivos, reales o imaginarios, en los y las creyentes corrientes para generar y agrandar permanentemente este nudo?

\section{La ternura de Dios}

el cristianismo masculinizó la imagen de Dios, eso es un hecho. A lo largo de la historia hubo muchas declaraciones de principios que aseguraron que Dios no tenía sexo; pero el lenguaje se encargó de determinarlo. en el mundo de la representación no es pensable una imagen asexuada, por ello el inconsciente colectivo eclesial suprimió poco a poco - en ocasiones intencionadamente, en otras menos - todos los aspectos femeninos de la Deidad judeo-cristiana. La Biblia tiene imágenes que apuntan a la Divinidad en femenino: Dios tiene entrañas de misericordia, es gestador y cuidador de vida; es claro que Jesús de Nazaret experimentó una filiación atravesada por la 
ternura respecto a su Dios, pero todo ello fue suprimido de la vida cotidiana de las iglesias en un proceso de abstracción por un lado y de masculinización por otro. La imagen preferida de los primeros siglos fue la de Cristo como esposo de la Iglesia.

es importante tener en cuenta además que el cristianismo arraiga en un ámbito, el mediterráneo, poblado fuertemente por imágenes femeninas de la Divinidad. Diosas que bendicen, que acompañan, que habitan el hogar y conducen a los viajeros. Diosas del amor y de la sabiduría, del fuego, de la tierra, de la luz. La Diosa madre, reina del cielo y de la tierra. Mayoritariamente, los líderes religiosos cristianos de los primeros siglos se lanzan en cruzada contra el mundo pagano y, en esa lucha, la parte más fuerte y más encarnizada correspondió a las representaciones humanas y divinas femeninas.

en este proceso, es claro que los aspectos de la Divinidad que se suprimieron impidieron a mujeres y hombres seguidores del evangelio alimentar dimensiones de su vida que les eran imprescindibles. La llamada al amor que realiza imperativamente el evangelio fue vaciada de contenidos reales y la ternura, necesidad humana profunda e imprescindible, quedó fuera de la experiencia religiosa:

La ternura supone el amor, pero no se identifica simplemente con él. La ternura nos habla de una dimensión específica de la manifestación del amor caracterizada por un dato de desbordamiento, sobreabundancia, exceso [...]. es el rostro vulnerable del amor que se nos acerca y entrega, a través de una exteriorización expresiva de delicadeza, cuidado, solicitud, dulzura [...], al mismo tiempo que ofertando protección, vigor y firmeza. Se acompaña de un dato de cercanía no necesariamente corporal -aunque habitualmente pase por el contacto- pero sí de proximidad profunda, intensa [...]. [es] una cercanía que busca la distancia de intimidad y que incluye junto al elemento del don gratuito el de una acogida empática, atenta y desinteresada (Martínez-Gayol, 2006, p. 20).

en el cristianismo, desde muy pronto, la imagen masculinizada de Dios se hizo adusta, exigente, vigilante. La espiritualidad fue pasando de la experiencia alegre de Jesús de Nazaret, que se emocionaba ante los pájaros y 
las flores o experimentaba la grandeza de Dios en los pequeños, a una cada vez más rigurosa ascética, que endureció permanente y progresivamente el rostro de Dios. Se pasó de la alegría del sentirse habitado por la Divinidad al temor de la culpa acechante.

este tipo de experiencia solo podía conducir a la neurosis religiosa que plagó los paisajes internos y externos de nuestras iglesias, convirtiendo a la mujer, el sexo y el afecto en enemigos de la Divinidad. La ternura, la cercanía, el amor en sus distintas manifestaciones necesariamente tienen que habitar la experiencia religiosa, porque se trata de sentimientos profundamente arraigados en el ser humano, profundamente liberadores y, en ocasiones, hondamente necesarios para la liberación:

Todos necesitamos saber que alguien nos quiere, y anhelamos un cariño incondicional que no dependa de nada, que no busque contrapartida, que no intente beneficiarse. Y no solo saberlo, sino experimentarlo, sentirlo, de algún modo palparlo. La ternura con la que el otro se nos aproxima resulta ser un espacio de contacto con ese afecto incondicional, con ese amor gratuito, siempre y cuando sea verdadera ternura (Martínez-Gayol, 2006, p. 72).

Si este campo de la vida humana se excluyó de la vivencia de la Divinidad, ¿cómo podían los teólogos seguir afirmando que Dios es amor? ¿qué querían decir con ello, más allá de una declaración de principios o un concepto vacío?

\section{María suple la necesidad}

La figura de María de Nazaret, la madre de Jesús, tempranamente llenó este vacío, tanto en el terreno de los sentimientos sencillos y cotidianos, como en el de la especulación teológica. ya en los mismos evangelios canónicos se inicia sutilmente esta dinámica. Cuando Juan pone a María a mediar ante Jesús para que garantice el vino en una fiesta, cuando la muestra acompañando a su hijo ajusticiado o cuando Lucas la hace viajar unos días a las montañas de Judea a visitar a una familiar de edad avanzada y envolver a su hijo recién nacido en pañales en mitad de la noche, no están haciendo otra 
cosa - con estas narraciones e imágenes - que configurar un rostro cercano, unos gestos que habitan, llaman y testimonian la ternura. en el otro extremo, Marcos pone en boca de Jesús una actitud más o menos despreciativa ante su madre: “¿quiénes son mi madre y mis hermanos?". y Pablo la ignora olímpicamente.

En mi opinión, la posición oficial de la Iglesia, en este terreno, siempre ha sido ambigua y poco definida. No ha sido exactamente la teología católica ortodoxa la que ha impulsado lo que podemos llamar la divinización de María. Algunas veces la ha tolerado, en otras ocasiones - las menos- la ha liderado. Tampoco ha sido la teología dogmática la que ha impuesto una imagen concreta de María, sino que ha sido impulsada muchas veces por curas de misa y olla (al decir de Cervantes) y por monjas sin mucha formación teológica. en otras ocasiones, esta imagen se ha impuesto desde algunos santuarios por intereses meramente económicos. La teología dogmática ha ido casi siempre a la zaga de las devociones populares, que han terminado por imponerse, como claramente se puede ver en la declaración del llamado dogma de la Asunción. Igualmente en el caso del Dogma de la Inmaculada concepción.

Rastreando los ejes por los que transcurrió esta exaltación de María, lo más corriente es ubicar un momento muy importante en el concilio de Éfeso, celebrado en el año 431. en él se concedió institucionalmente a María de Nazaret el título de Madre de Dios (Theotokos) y la imagen de esta humilde campesina judía asumió plena y abiertamente las características que se le sumaron soterradamente a lo largo de al menos dos siglos: todas las notas que correspondían a la diosa de Éfeso, conocida como la Reina del cielo.

La imagen arquetípica femenina siempre ha estado habitada por deseo y temor, por amor y por odio, por refugio y rechazo. Los conocidos como padres de la Iglesia separaron estos dos aspectos que la mujer inspira a los hombres en la cultura occidental: el que podríamos considerar positivo (amor, refugio) y el que podríamos considerar negativo (temor, rechazo), concentrando en eva todos las cargas negativas y liberando a María de cualquier oscuridad posible. en un proceso mestizo, en el que se conjugan sueños, preguntas, deseos, temores e intereses, se va gestando esa María madre, más o menos diosa, consoladora en ocasiones, virgen que impone su maternidad extraordinaria en otras. Julia Kristeva lo describe así: 
A partir de este material programático pero escaso, proliferará un imaginario irresistible que tomará fundamentalmente tres direcciones. Por una parte se tratará de homologar a la Madre con el Hijo desarrollando el tema de la inmaculada concepción e inventando una biografía de María análoga a la de Jesús, y de privarla de la muerte, privándola del pecado: María fallece en dormición o asunción. Seguidamente se trata de darle cartas de nobleza, un poder que, aunque se ejerza en el más allá, no es por ello menos político, ya que María será proclamada reina, dotada de los atributos y los boatos de la realeza y, paralelamente, declarada Madre de la institución divina en la tierra, la Iglesia. Finalmente, la relación con María y de María será considerada como prototipo de la relación de amor y asumirá, con este fin, dos aspectos fundamentales del amor occidental: el amor cortesano y el amor del niño, adoptando así toda la gama que va de la sublimación al ascetismo y al masoquismo (1987, p. 212).

este proceso, en ocasiones, ha resultado imparable y, por supuesto, incontrolable: de ahí la urgencia de la Iglesia de frenarlo muchas veces, la mayoría de ellas sin éxito.

\section{Hacia la divinización: el tránsito, la dormición}

ya me he referido de paso al proceso de divinización, que se inició muy pronto. La obra más perfilada en este sentido es el Protoevangelio de Santiago, en el que se escribe íntegramente la vida de María de Nazaret, tratando de responder a cualquier inquietud posible y sin dejar lagunas.

el texto se construye bajo los parámetros de las vidas de héroes, comunes en la literatura bíblica y en otras literaturas de la Antigüedad. en primer lugar, no se inserta en la tradición de los pobres de Yhwh, sino que nos encontramos con Joaquín, un hombre rico: María nace entre los notables de su pueblo. Junto a esta ubicación, algo que no puede faltar: el nacimiento milagroso o prodigioso, como en otros casos de la tradición bíblica (Samuel, Juan Bautista). La elección se manifiesta en que Dios, primero, hace estéril a 
la madre y, posteriormente, sacraliza su vientre con un fruto de vida que, al ser bendecido y especial, será santo.

en este caso, la concepción será igualmente milagrosa. el relato no se detiene mucho en ello, pero es claro que proyecta sobre la concepción de María por parte de sus padres la propuesta de Lucas sobre la concepción de Jesús. estando ausente Joaquín, su esposa, Ana, concibe por obra de Dios. De esta manera, este texto define muy tempranamente las coordenadas que harán pensable el dogma de la Inmaculada Concepción.

el relato continúa y, para alejar de María toda sombra de duda en torno a su piedad, religiosidad y pureza, pero también en torno a un ambiente en el que hubiera podido ser violada - cosa más o menos corriente en su país y en su época-, nos cuenta que desde temprana edad es llevada al templo y consagrada a servir en él sin salir más: de nuevo proyecta sobre María las características de Samuel. Se introducen elementos maravillosos y fantásticos, que alejan el texto de tradiciones más austeras, como las canónicas: la niña danza, camina y bendice, más allá de las posibilidades y de las expectativas de su edad.

Miremos en detalle las creencias en la dormición de María, llamada igualmente el tránsito, que posteriormente la Iglesia recoge como dogma con el nombre de la Asunción. es difícil situar con precisión el origen de los relatos que sustentan la creencia en la asunción. el primer testimonio parece que lo constituye el evangelio apócrifo llamado Tránsito de la Bienaventurada Virgen María, en el que en el numeral 3 del capítulo 1 se dice: "Juan, apóstol, evangelista de zebedeo y autor de esta historia" (Borges, 1988, p. 391). Hay relativo consenso en el sentido de que este es el primer relato que circuló sobre la dormición y el tránsito, pero no existe unanimidad sobre la fecha de composición: algunos lo ubican muy tempranamente, en el siglo II; otros tardíamente, en el siglo V. quienes lo sitúan como más tardío reconocen, en todo caso, que conserva versiones muy anteriores. esto por lo que respecta a la tradición conocida como apócrifa. en las voces más eclesiales, hay evidencia de que epifanio (315-403) no dudaba del tránsito de María, rodeado además de muchos hechos milagrosos (Bover, 1951).

Gonzalo Aranda Pérez, en su estudio "La asunción de María en los apócrifos", afirma que el primer texto que circula sobre el tema es el libro etiópico llamado Libro del reposo de María. este autor dedica varias páginas a este 
texto de compleja estructura y enrevesada teología, con influencia gnóstica (2000, pp. 35-68). La narración mezcla varios temas, desde la dormición de María hasta una versión muy inédita de la Trinidad. No se ha logrado establecer la fecha de composición, pero es claro que responde a un ambiente cercano al siglo II y que además otorga mucha importancia al Primer Testamento, lo que hace pensar en un contexto de influencia hebraica.

Un testimonio muy significativo es la homilía de Cirilo, obispo de Jerusalén, pronunciada en la fiesta del 16 de Mesoré (equivalente al 9 de agosto del calendario juliano). esta homilía, a la que tenemos acceso en su totalidad por la edición y traducción de Pilar González Casado (2002), ya contiene todos los elementos de la fábula que va a constituir en adelante lo esencial de estos relatos.

Este tema nace al margen de las declaraciones oficiales de la Iglesia, pero la va penetrando. Su importancia está explicitada por Julia Kristeva en estos términos:

La realización, bajo el nombre de María, de una totalidad compuesta de mujer y de Dios, se produce finalmente por la evitación de la muerte. La Virgen Madre conoce una suerte más radiante que la de su hijo: al haber sufrido el calvario; no tiene tumba, no muere y por tanto no tiene necesidad de resucitar. María no muere, sino que -como en un eco de las creencias orientales, entre otras taoístas, en las que los cuerpos humanos pasan de un lugar a otro en ese flujo eterno que es en sí mismo un calco del receptáculo materno - transita (1987, p. 216).

La dormición, el tránsito, la asunción, proporcionan plenitud a la divinización de María de Nazaret.

A partir del siglo VI la asunción hace parte, de diferentes formas, de las celebraciones litúrgicas, tanto en las iglesias de Oriente como en las de Occidente. en las homilías mariológicas de Germán de Constantinopla (640-730) se recogen los elementos que posteriormente serán retomados en todos los relatos de la dormición. en su Homilía VI, leemos:

ya ha llegado el tiempo - dice el Señor - de llevarte conmigo, oh Madre. Así como llenaste de gozo toda la tierra y a cuantos en ella habitan, oh llena de gracia, así también ahora llenarás de alegría los cielos. Regocija, pues, las mansiones de mi padre y las almas de los santos. 
Viendo estos tu glorioso tránsito hacia mí con la escolta de los ángeles, obtienen, por la fe, la seguridad de que también ellos, gracias a ti, han de tener parte conmigo habitando mi luz [...]. He aquí que vienen hacia ti mis discípulos, hijos espirituales de mi luz, los cuales con reverencia y honor, cuidarán de tus honras fúnebres. Tú misma eres testigo de que yo les concedí la gracia de la adopción filial (1991, pp. 133-137).

Manteniendo el género de homilía, se mezclan elementos de los relatos que circulan tanto desde la imaginación como de la propia interpretación de los evangelios. De esta manera lo marginal, lo apócrifo - en ocasiones condenado-, se va haciendo central y va siendo recogido por el tronco. es una de las formas en que lo popular logra hacer parte de la cultura en el sentido más elitista.

Germán de Constantinopla muestra cómo se va generando en los y las fieles creyentes el imaginario materno ligado a María. Ese imaginario que Jung aborda en los siguientes términos:

El aspecto positivo de la hipertrofia del instinto maternal, es esa imagen de la madre que ha sido cantada y ensalzada en todos los tiempos y todas las lenguas. es ese amor de madre que cuenta entre los recuerdos más emotivos e inolvidables que se tienen en la edad adulta y que constituye la secreta raíz de todo devenir y todo cambio, la vuelta a la paz del hogar y el último y silencioso fundamento de todo principio y todo fin (2010, p. 88).

Con las bendiciones, contradicciones y tremendas dificultades que esa imagen comporta:

entrañablemente cercana y ajena como la naturaleza, amorosamente tierna y fatalmente cruel [...], una gozosa e inagotable dadora de vida, una madre dolorosa y la puerta tenebrosa y sin respuesta que se cierra detrás del muerto [...]. Porque precisamente ese cúmulo de hondo significado es lo que nos deja a nosotros ligados a la madre y a ella encadenada al hijo, para ruina física y psíquica de ambos (p. 88). 


\section{El misterio de Elche}

Con el Misteri, o Festa d'Elx, declarado en 2001 por la Unesco Obra Maestra del Patrimonio Oral e Inmaterial de la Humanidad, tenemos, a mi juicio, un testimonio invaluable, viviente y actuante, de procesos, teologías y relatos que se han ido configurando por siglos en las tradiciones populares y eclesiales. Se trata de una obra de estructura compleja, que habla simultáneamente a la razón-comprensión, a los sentimientos-emociones, a la experiencia religiosa y a la estética. Todo ello alrededor de la experiencia que los ilicitanos tienen de la Mare de Déu. estamos ante una de las obras en las que la inculturación ha logrado una expresión cercana a lo perfecto.

en su hermoso libro sobre la Festa, María Ángeles Sánchez lo dice así:

Nuestra Festa es épica y lírica, experiencia íntima y memoria colectiva, relación directa con la divinidad y mirada común sobre el género humano. es también un tremendo acto de amor, una suprema prueba de generosidad de la ciudad de elche hacia el mundo entero (2000, p. 23).

y en torno a la totalidad de la representación, señala:

Arropando este discurso teológico, emotivo, teatral (el Misteri es la única supervivencia ininterrumpida de nuestro teatro medieval) y eminentemente popular, siglos y siglos de acordes musicales, palabras, gestos, elementos escenográficos y miles de voluntades aunadas para que los ilicitanos del tercer milenio, y cuantos con ellos quieren compartirlo, puedan disfrutar del más hermoso de los legados (p. 23).

Es, como dije, la culminación de un proceso de siglos. El relato contiene todos los elementos centrales que estructuran la fábula sin que haya extrapolaciones extrañas que distraigan la atención o carguen el texto de densidades teológicas: María se enferma, los discípulos son llamados de distintas partes del mundo para asistir a sus últimas horas. Tomás llega tardíamente, Juan es la figura central entre ellos. Los judíos amenazan desde su no aceptación de los hechos, pero finalmente se convierten ante la evidencia del milagro. La dormición, la asunción y finalmente la coronación de María por manos de la Trinidad, que la instituye como reina universal de todo lo creado, según el sentir popular. Los estudiosos, en su gran mayoría, aceptan que el texto, 
tal como se mantiene y representa, sigue muy de cerca el hilo de La leyenda dorada, compuesta por Jacobo de Varazze antes de 1270 y que depuró mucho el conjunto de leyendas, que en ocasiones se enmarañó.

Lo que me interesa destacar ahora es el sentimiento popular recogido en esta fiesta y representación, en la que lo más importante para nuestro tema es la realización y actualización, el 15 de agosto de cada año, de la divinización permanente y renovada de María de Nazaret. Sin embargo, quiero referirme a un aspecto que puede proporcionarnos luces para reflexiones futuras, a causa de su actualidad. Sobre el Misteri teológico, señala Francisco Conesa Ferrer, estudioso de los diálogos entre fe y cultura:

Nos sorprende por la fuerza en que lo corporal aparece tratado. Podemos encontrar en el texto del Misteri los principios de una auténtica teología cristiana del cuerpo. esta teología se desarrolla en el segundo acto, una vez que ha tenido lugar la muerte de María. Tras entregar la palma a Juan, Pedro y los apóstoles se arrodillan alrededor del túmulo y prorrumpen en un canto que se dirige, precisamente, al cuerpo de María: Pregantvos cos molt sagrat. es un verdadero canto al cuerpo, a lo corporal, que es llamado sagrado y santo (2000, p. 150).

Jung confirma este planteamiento:

La psicología tiende a ver en el dogma de la Asunción un símbolo que anticipa en cierto sentido la reconciliación materia-espíritu. La psicología considera las relaciones con la tierra y con la materia como una propiedad indispensable del arquetipo de la madre. Así pues, si a una figura condicionada por tal arquetipo se la presenta como acogida en los cielos, es decir, en el reino del espíritu, se ha insinuado así una unión del cielo y la tierra, o del espíritu y la materia [...]. Pero entendida simbólicamente, la assumptio del cuerpo significa el reconocimiento de la materia, que solo debido al predominio de la tendencia neumática había acabado siendo identificada con el mal por excelencia (2010, p. 103).

Con el Misterio de elche (Alicante, españa) asistimos en pleno siglo XXI a una recopilación de las tradiciones populares de María como figura maternal-divina, que consuela y protege. Recoge tradiciones prioritariamente 
europeas, pero igualmente de toda la cristiandad. María Ángeles Sánchez, en su libro citado, dedica el libro: "y a mi madre que, nacida en Madrid, se enorgullece de llevar una medalla con la Virgen de la Asunción y la Virgen de la Paloma juntas". y como ella, cientos de miles de mujeres, madres o hijas, para quienes esa figura es la ternura de Dios.

\section{En América Latina}

Las advocaciones se multiplican por doquier, en cada país, en cada región, en cada pueblo. Por un lado, están las comunes a distintas regiones: la Virgen de la Candelaria, la del Carmen, la Dolorosa, la de las Mercedes, la Virgen del Rosario, María Auxiliadora... Por otro, las más particulares: la Aparecida en Brasil, Nuestra señora de Guadalupe en México, la Virgen del Cobre en Cuba, Chiquinquirá y las Lajas en Colombia, la Divina Pastora en Venezuela, la Virgen de los Ángeles (La Negrita) en Costa Rica, Nuestra Señora del quinché y Nuestra Señora del Cisne en ecuador, la Virgen de Copacabana en Perú... Todas ellas, la madre divina que protege.

Me impresionó mucho escuchar a José esaú Guetio, indígena nasa, quien el 18 de julio de 2012 se dirigió a los militares colombianos tras el asesinato de su sobrino a manos del ejército, a quienes siempre había apoyado en su pequeña parcela: "Nuestra Señora la Virgen Santísima los bendiga y los perdone, porque yo no puedo perdonarlos". Una vez más, se invoca la figura de la Virgen para que supla lo que no alcanzamos a hacer como seres humanos.

María en el pueblo latinoamericano, en los santuarios y devociones, pero sobre todo en la vida diaria y cotidiana, en medio de angustias y dolores, es - más allá de toda teología o dogmática - la madre divina que consuela. Las mujeres de las Comunidades eclesiales de Base $(\mathrm{CeB})$ en todo el continente la invocan y cantan en estos términos:

Madre de los pobres hay mucha miserial porque falta siempre el pan en muchas casas/ el pan de la verdad falta en muchas mentes/ el pan del amor, que falta en muchas gentes./ Mientras recorres la vida, / tú nunca sola estás, / contigo por el camino/ Santa María va./ Virgen morenita, virgen milagrosa/ Virgen 
morenita te elevo mi cantar/ son todos en el Valle devotos de tus ruegos, / son todos peregrinos, Señora del lugar.

el pueblo creyente y sencillo, aquel que todavía mantiene lo que muchas veces se ha llamado la fe del carbonero, encuentra en María esa mujer popular y pobre, sí, pero con poderes divinos que se sienten más como luz y consuelo que como milagros extraordinarios. Las mujeres experimentan en su sabiduría que las cosas no van a cambiar ni por su propia mano ni por la de Dios; pero sus daños y dolores son consolados por esa madre universal y amiga.

en los barrios de nuestras ciudades no se ve en María una supuesta virtud de modestia o virginidad, ni tampoco una especie de supermujer milagrera que les solucionaría sus problemas, ni tampoco una reina lejana. Saben que parió con dolor en un pesebre porque fue rechazada en la posada, saben que una espada atravesó su corazón porque ajusticiaron a su hijo. Sienten que esa figura que las antecedió en la pena las ilumina y las consuela. Poco importa lo que digan los padres en la Iglesia sobre esta imagen, ellas no saben de dulías... Lo que importa es su experiencia íntima de consuelo: María, en sus vidas, está más allá de cualquier otro paradigma.

\section{Referencia}

Aranda Pérez, G. (2000). La asunción de María en los apócrifos. en Conesa Ferrer, F. \& Rodríguez Tribes, F. (eds.). La asunción de María en la teología y en el Misteri $d^{\prime} E l x$ (pp. 35-68). elche: Patronato Nacional del Misteri d'elx.

Arias, J. (2005). María, esa gran desconocida. Madrid: Maeva.

Borges, J. L. (1988). Evangelios apócrifos (Vol. II). Barcelona: Orbis.

Bover, J. M. (1951). La Asunción de María. Madrid: Biblioteca de Autores Cristianos.

Conesa Ferrer, F. (2000). La teología asuncionista del Misteri d elx. en Conesa Ferrer,

F. \& Rodríguez Tribes, F. (eds.). La asunción de María en la teología y en el Misteri $d^{`} E l x$ (pp. 35-68). elche: Patronato Nacional del Misteri d'elx.

De Constantinopla, G. (1991). Homilías mariológicas. Madrid: Ciudad.

González Casado, P. (ed.). (2002). La dormición de la Virgen, cinco relatos árabes. Madrid: Trotta. 
Halkes, C. (2000). María en mi vida. en Schillebeeckx, e. \& Halkes, C. (eds.). María ayer, hoy, mañana (González Iglesias, L. Trad.). Salamanca: Sígueme. (Trabajo original publicado en 1992).

Johnson, e. A. (2005). Verdadera hermana nuestra, teología de María en la comunión de los santos. Barcelona: Herder.

Jung, C. G. (2010). Los arquetipos y lo inconsciente colectivo (Obra completa, Vol. 9 / 1). Madrid: Trotta.

Kristeva, J. (1987). Stabat Mater. en Historias de amor (pp. 209-231). México, D. F.: Siglo XXI.

Martínez-Gayol, N. (2006). Un espacio para la ternura: miradas desde la teología. Madrid: Universidad Pontificia de Comillas.

Orígenes. (2001). Contra Celso. Madrid: Biblioteca de Autores Cristianos.

Sánchez, M. Á. (2000). La Festa d'Elx. Madrid: Ayuntamiento de elche. 
